\title{
Pelatihan Internet Sehat dalam rangka Pemanfaatan Internet Gratis di Desa Mengwi Kabupaten Badung
}

\author{
${ }^{1 *}$ Komang Rinartha, ${ }^{2}$ I Gede Harsemadi, \\ ${ }^{3}$ Luh Gede Surya Kartika \\ Sistem Komputer, Institut Teknologi dan Bisnis STIKOM Bali ${ }^{1}$ \\ *Email: komangrinartha@gmail.com
}

\begin{abstract}
ABSTRAK
Pemerintah Kabupaten Badung menggulirkan program fasilitas internet gratis kepada masyarakat Badung. Salah satunya, di Desa Mengwi, titik akses internet tersebut diletakkan di masing-masing Balai Banjar. Ketua Karang Taruna Wiratama Mandala Desa Mengwi menjelaskan bahwa masyarakat di Desa Mengwi umumnya memanfaatkan fasilitas internet gratis tersebut untuk sosial media atau game online. Karang Taruna Desa Mengwi merasa bahwa pemanfaatan internet gratis di Desa Mengwi belum mengarah pada kegiatan berinternet yang aman dan sehat. Karang Taruna menginginkan agar masyarakat di Desa Mengwi memperoleh edukasi mengenai pemanfaatan internet dengan baik. Solusi yang disepakati bersama antara pengurus Karang Taruna Wiratama Mandala Desa Mengwi dan tim pelaksana kegiatan adalah dilakukannya pelatihan internet sehat dan bermanfaat. Tujuan kegiatan tersebut agar masyarakat dapat mengetahui cara memanfaatkan internet dengan aman dan baik. Realisasi kegiatan pada 5 januari 2020, bertempat di Balai Banjar Peregae Desa Mengwi. Peserta yang hadir adalah warga Banjar Peregae Desa Mengwi yang telah diundang oleh Karang Taruna Wiratama Mandala Desa Mengwi. Hasil evaluasi kegiatan menunjukkan bahwa peserta telah memahami materi yang diberikan. Kegiatan telah berlangsung dengan baik, di mana penilaian kinerja kegiatan ini memperoleh nilai 47 dari rentang nilai 11-55. Kegiatan yang terlaksana telah dapat bermanfaat bagi masyarakat mengimplementasikan penggunaan internet sehari-hari.
\end{abstract}

Kata kunci : Internet sehat, Desa Mengwi

\section{ABSTRACT}

The Government of Badung Regency has rolled out a free internet facility program for the Badung community. One of them, in Mengwi Village, the internet access points are located at each Banjar Hall. The head of the Karang Taruna Wiratama Mandala, Youth Organization of the Mengwi Village, explained that people in Mengwi Village generally use the free internet facility for social media or online games. The Mengwi Village Youth Organization feels that the use of free internet in Mengwi Village has not led to safe and healthy internet activities. Karang Taruna wants the people in Mengwi Village to get education about the use of the internet properly. The solution that was mutually agreed upon between the management of the Karang Taruna Wiratama Mandala, Mengwi Village and the activity implementation team was to conduct healthy and useful internet training. The purpose of 
these activities is so that people can know how to use the internet safely and well. Realization of activities on January 5, 2020, at the Peregae Banjar Hall, Mengwi Village. Participants who attended were residents of the Banjar Peregae, Mengwi Village who had been invited by the Wiratama Mandala Youth Organization, Mengwi Village. The results of the evaluation of the activities show that the participants have understood the material given. The activity has been going well, where the performance appraisal of this activity gets a value of 47 from the 11-55 score range. The activities carried out have been beneficial for the community in implementing daily internet use.

Key words: healthy internet counseling, Mengwi Village

\section{PENDAHULUAN}

Perkembangan Internet di era globalisasi saat ini telah berkembang semakin pesat. Di Indonesia, pengguna internet mencapai 150 juta jiwa dengan penetrasi $56 \%$ yang tersebar di seluruh wilayah. Jumlah tersebut hanya selisih sedikit dengan jumlah pengguna internet mobile yang berjumlah 142.8 juta jiwa dengan persentase penetrasi sebesar 53\% (Kominfo, 2019). Masyarakat menggunakan internet dengan tujuan untuk berkomunikasi, fasilitas pekerjaan, hingga untuk kepentingan mengakses data dan informasi (Abdi \& Rachman, 2017). Menurut Krisnawati (2015), semakin banyak remaja memilih internet untuk mencari informasi, selain itu media yang paling sering digunakan untuk mengakses internet adalah mobile. informasi yang paling sering dicari oleh remaja di internet adalah mencari informasi tentang hobi dan hiburan. Indo Telko (2018) menyatakan bahwa "sebanyak 91\% generasi muda Indonesia menyatakan bahwa internet semakin mendorong mereka memiliki semangat wirausaha dan $83 \%$ berniat atau sudah mendirikan bisnis online". Para pelaku usaha di sektor internet, termasuk para pemuda di pedesaan termotivasi untuk terus berkreasi dan berwirausaha dengan memanfaatkan internet, meskipun mereka hidup di pedesaan (Yusup, 2019).
Namun, selain memberikan beragam keuntungan, penggunaan internet khususnya dalam sosial media juga menghasilkan dampak negatif seperti penipuan (Rusmana, 2015), fenomena cyberbullying pada remaja (Rufaudin, 2016; Utami dan Baiti, 2018; Maya, 2015; Rachmatan, R., \& Ayunizar, 2017).

Pemerintah Kabupaten Badung menggulirkan program fasilitas wifi atau internet gratis kepada masyarakat Badung. Sebagai bagian dari kabupaten Badung, Desa Mengwi juga memperoleh manfaat dari program tersebut. Titik akses internet tersebut diletakkan di masing-masing Balai Banjar di Desa Mengwi. Sedikitnya ada 892 titik dengan kurang lebih 1.900 jaringan internet yang dipasang tahun 2018. Sekitar Rp 30 miliar dianggarkan untuk program tersebut, bahkan telah dipasang menara kamuflase berbentuk menyerupai pohon (Bali Express, 2018).

Ketua Karang Taruna Wiratama Mandala Desa Mengwi menjelaskan bahwa remaja dan paruh baya di Desa Mengwi umumnya memanfaatkan fasilitas internet gratis tersebut untuk sosial media atau game online. Karang Taruna merasakan bahwa pemanfaatan internet gratis di Desa Mengwi belum mengarah pada tujuan yang positif dan penggunaannya tidak efisien. Selain itu, dalam penggunaan media sosial, banyak 
warga di Desa Mengwi masih belum bijak. Ada di antara warga yang menggunggah hal-hal yang sangat pribadi sehingga mengancam keselamatan/keamaan pribadi, menggunggah hal-hal yang berbau SARA, menggunggah hal-hal yang mengarah pada pornografi, dan lainnya.

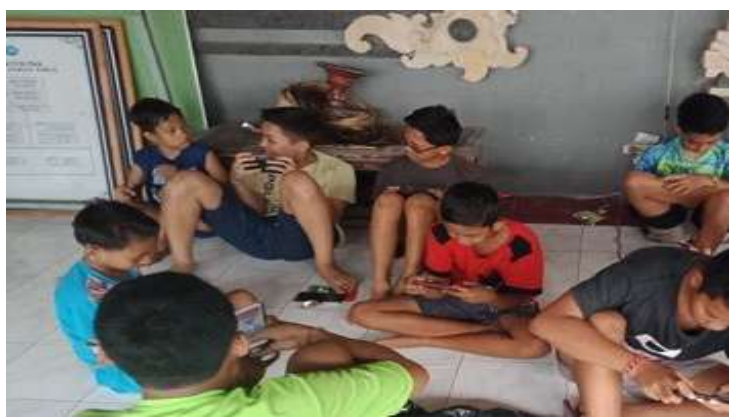

Gambar 1. Pemanfaatan Internet Gratis di Balai Banjar

Sebagai salah satu lembaga yang berperan aktif dalam memajukan Desa Mengwi, Karang Taruna menginginkan agar remaja dan paruh baya di Desa Mengwi memperoleh edukasi mengenai pemanfaatan internet dengan baik dan penggunaan internet untuk kemajuan perekonomian Mengwi. Solusi yang disepakati bersama antara pengurus Karang Taruna Wiratama Mandala Desa Mengwi dan tim pelaksana kegiatan adalah dilakukannya pelatihan internet sehat dan pelatihan digital marketing di Desa Mengwi. Kelanjutan dari kegiatan Karang Taruna lainnya dalam hal mengedukasi masyarakat. Di awal tahun 2019, dengan membawa bendera STIKOM Bali, juga telah dilaksanakan kegiatan pelatihan Bahasa Inggris dan pembuatan iklan pariwisata guna mendukung pariwisata Mengwi.

Karang Taruna Desa Mengwi membawahi 12 Sekeha Taruna Taruni pada masing-masing Banjar di Desa Mengwi, yaitu:

a. STT Dharma Kumara - Banjar Delod Bale Agung

b. STT Dharma Asih - Banjar Lebah Pangkung

c. STT Taman Swastika - Banjar Alangkajeng

d. STT Widjana Karya - Banjar Peregae

e. STT Yowana Dharma Casana - Banjar Munggu

f. STT Wira Bhakti-Banjar Pande

g. STT Dwarawati - Banjar Gambang

h. STT Niti Dharma Sutra - Banjar Batu

i. STT Wahana Budi Satia - Banjar Pandean

j. STT Cura Dharma - Banjar Serangan

k. STT Garuda - Banjar Pengiasan

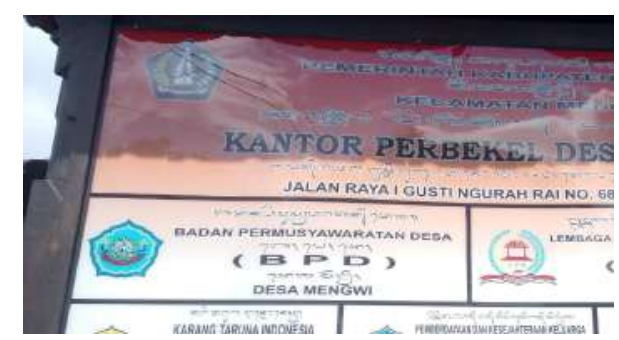

Gambar 2. Nama Karang Taruna Wiratama Mandala di Papan Kantor Perbekel Desa Mengwi

Apabila diperhatikan dari segi ekonomi, masyarakat Mengwi memiliki potensi yang besar dalam hal industri pariwisata, makanan olahan, serta hiasan untuk tempat ibadah. Hasil penuturan Ketua Karang Taruna, industri pariwisata di Desa Mengwi telah mengalami kemajuan yang pesat dengan bantuan promosi pariwisata baik dalam lokal maupun mancanegara. Masyarakat pada sektor industri makanan olahan dan hiasan untuk tempat ibadah juga memerlukan edukasi mengenai pola pemasaran non konvensional agar produk dari masyarakat 
Mengwi memiliki jangkauan pasar yang lebih luas.

\section{RUMUSAN MASALAH}

Berdasarkan pemaparan analisis situasi, permasalahan mitra Karang Taruna Desa Mengwi adalah sebagai berikut.

1. Remaja dan paruh baya di Desa Mengwi belum seluruhnya memahami mengenai internet sehat. Pada penggunaan internet sehat khususnya sosial media, masih terdapat warga yang belum bijak dalam mengunggah konten/informasi dalam akun mereka.

2. Pemanfaatan program internet gratis oleh Pemerintah Kabupaten Badung menurut Karang Taruna di Desa Mengwi masih belum optimal. Internet gratis hanya dimanfaatkan untuk game online dan sosial media. Karang Taruna Desa Mengwi merasa perlu untuk mengedukasi remaja dan paruh baya di Desa Mengwi dalam optimalisasi pemanfaatan internet gratis.

\section{METODE}

Setelah merumuskan permasalahan, solusi yang disepakati dengan pengurus Karang Taruna Desa Mengwi adalah dilaksanakannya pelatihan internet sehat, khususnya dalam penggunaan sosial media. Pelatihan ini dilakukan untuk mengingatkan warga Mengwi mengenai keamanan, kesehatan fisik dan emosional, dampak sosial dan hukum dalam penggunaan internet yang tidak sehat.

Kegiatan ini merupakan lanjutan dari kegiatan sebelumnya yang dilaksanakan di Desa Mengwi. Pada awal Januari 2019, tim pelaksana dari Institut Teknologi dan Bisnis STIKOM Bali telah melaksanakan kegiatan sejenis di salah satu Banjar di Desa Mengwi yaitu "Peningkatan
Kemampuan Teknologi Sekeha Teruna Teruni Banjar Pandean dalam Mempersiapkan Smart Village", dan "Pelatihan Fotografi dan Photoshop di Banjar Batu Desa Mengwi". Namun, kegiatan kali ini bekerjasama dengan Karang Taruna Wiratama Mandala Desa Mengwi, agar dapat menjangkau seluruh masyarakat di Desa Mengwi tidak hanya salah satu Banjar saja.

Kegiatan pengabdian masyarakat ini dilaksanakan dengan prosedur yang ditunjukkan melalui Gambar 3 berikut
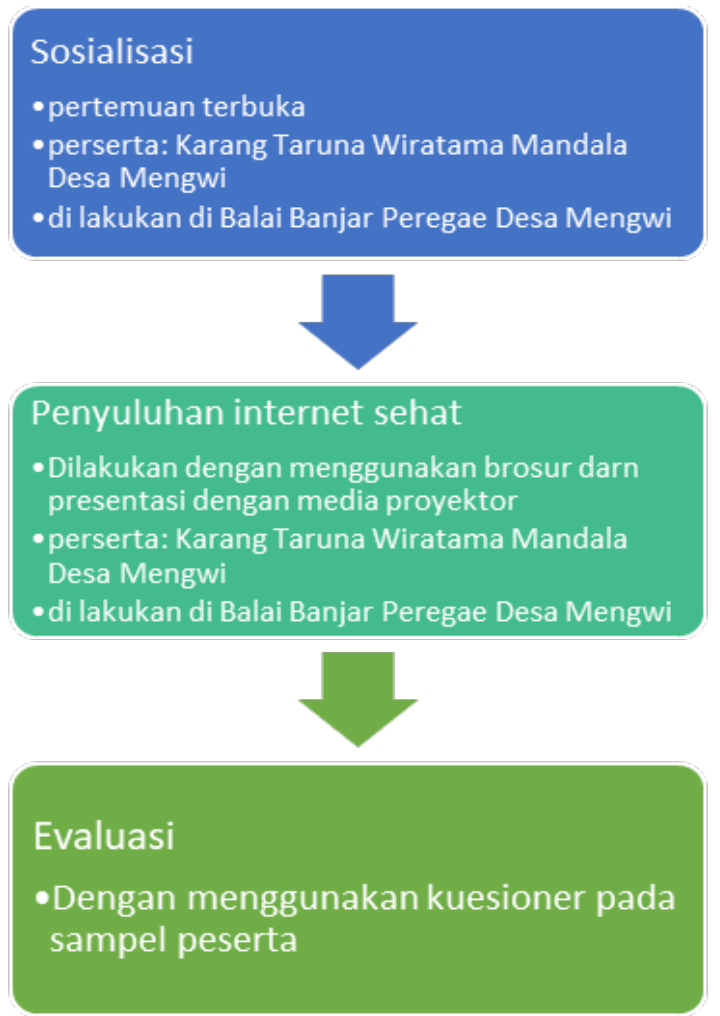

Gambar 3. Prosedur Kegiatan

Prosedur kegiatan pada Gambar 3 dijabarkan dalam bentuk rencana kegiatan berikut: 


\section{Sosialisasi}

Kegiatan sosialisasi dilakukan bertujuan untuk mengenalkan anggota tim dengan peserta pengurus dan anggota Karang Taruna Wiratama Mandala serta perwakilan masingmasing STT di Desa Mengwi. Kegiatan ini juga membahas agenda pelatihan dan penjadwalan kegiatan. Sosialisasi dilaksanakan dengan pertemuan terbuka di Kantor Kepala Desa Mengwi.

\section{Pelatihan internet sehat}

Kegiatan paparan materi dan pelatihan dilakukan dengan mengumpulkan peserta dalam satu pertemuan. Kegiatan dilakukan dengan bantuan media komputer, slide presentasi dan pemberian modul pelatihan. Pada awal kegiatan dilaksanakan pre-test yang digunakan untuk memahami pengetahuan dasar peserta tentang pokok bahasan materi. Di akhir kegiatan dilaksanakan post-test untuk mengetahui sejauh mana pemahaman peserta terhadap keseluruhan materi yang telah diberikan.

Tim pelaksana pengabdian terdiri dari dosen yang telah berpengalaman dalam pengembangan teknologi informasi dan komunikasi. Tim pelaksana juga telah melaksanakan kegiatan sejenis di salah satu Banjar di Desa Mengwi yaitu "Peningkatan Kemampuan Teknologi Sekeha Teruna Teruni Banjar Pandean dalam Mempersiapkan Smart Village", dan "Pelatihan Fotografi dan Photoshop di Banjar Batu Desa Mengwi”.

\section{PEMBAHASAN}

Pemaparan materi internet sehat telah dilaksanakan pada tanggal 5 Januari 2020 bertempat di Balai Banjar Peregae Desa Mengwi. Kegiatan dilaksanakan selama satu hari.

Kegiatan dilaksanakan dalam bentuk pemaparan materi dengan menghadirkan peserta dalam satu lokasi. Peserta diminta untuk mendengarkan dan mendiskusikan hal mengenai internet sehat dalam pemanfaatan fasilitas internet yang diberikan oleh pemerintah. Materi yang disampaikan pada saat paparan adalah sebagaimana ditampilkan pada brosur di Gambar 4 dan 5.

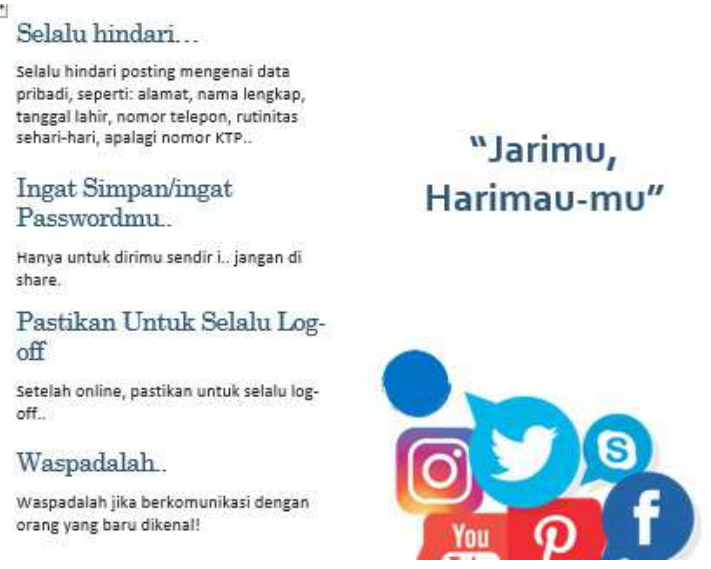

Gambar 4. Tampilan Depan Brosur internet sehat 


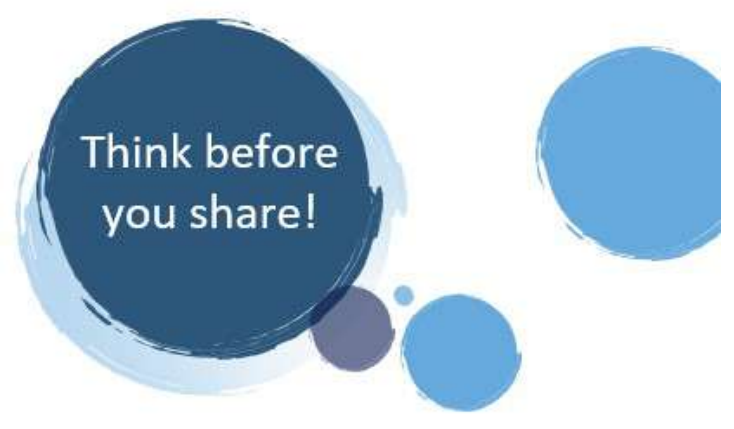

Sebelum shoring/bagikan, pikirkanlah dahulu kosenkuensi jika membagikan informasi tersebut. Membagikan informasi y
benar (HOAX) sangat berbahaya!

Hindari Penghinaan SARA

Bahkan Universitas Harvard Tolak Calo Mahasiswa karena Komentar Rasis di Medso

Gambar 5. Tampilan Belakang Brosur internet sehat

Bukti pelaksanaan kegiatan ditunjukkan oleh foto-foto pada Gambar 6 berikut ini:
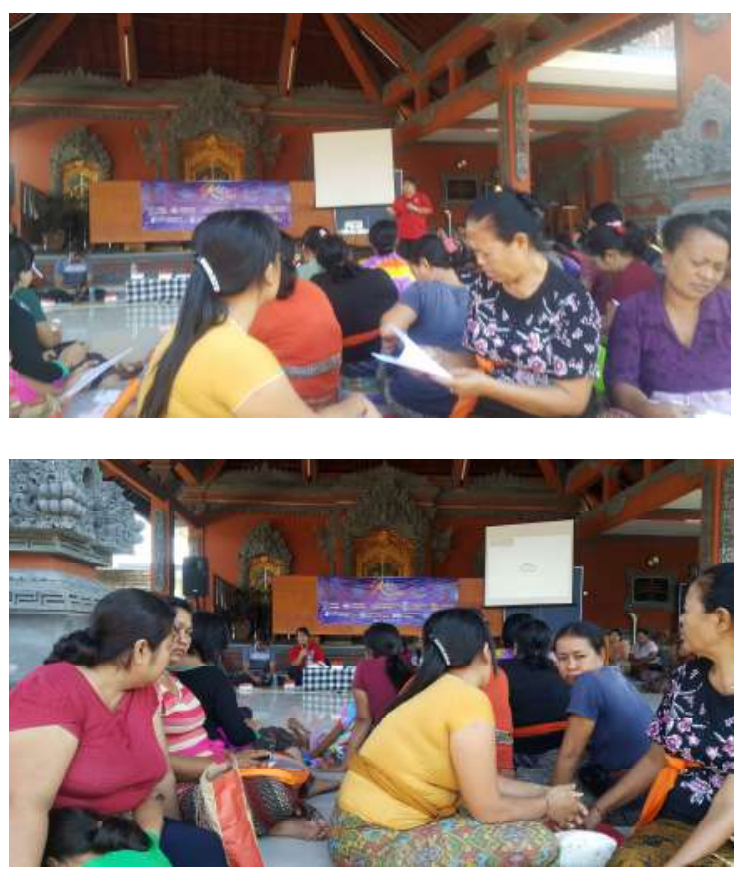
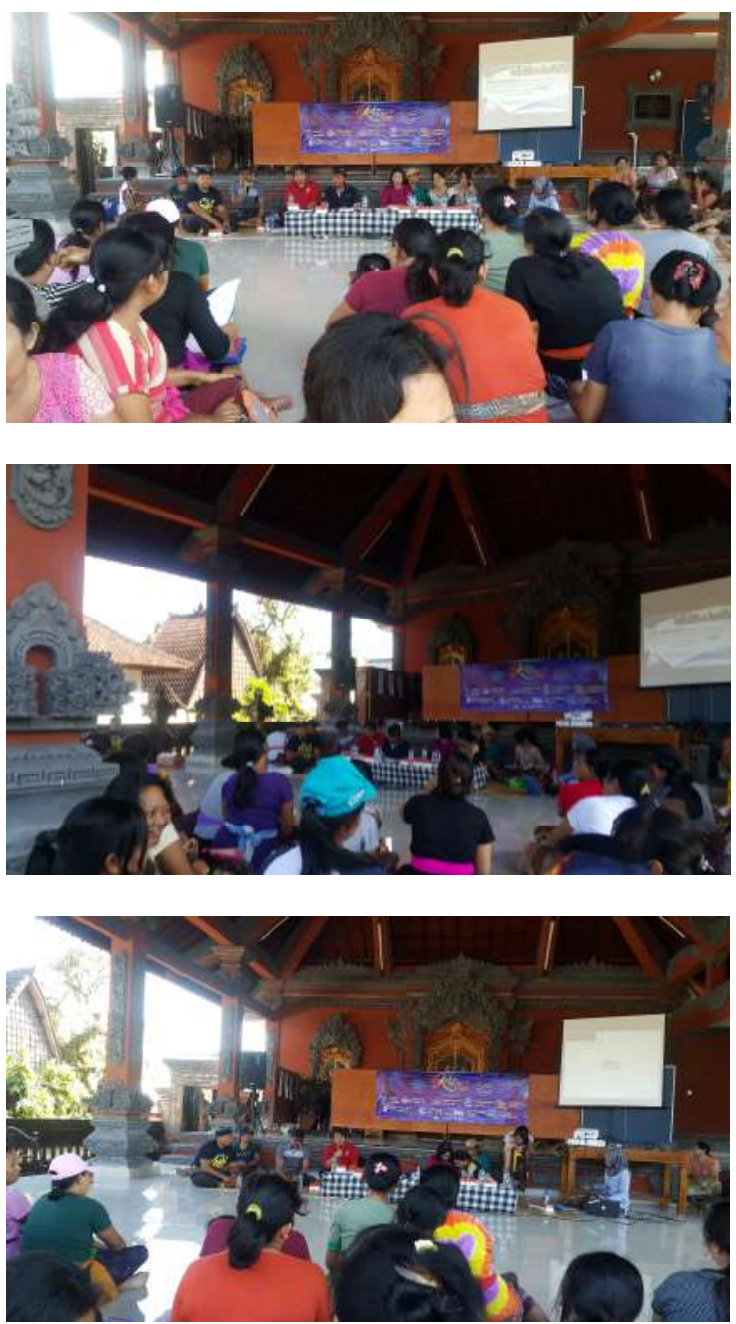

Gambar 6. Rangkaian Kegiatan Pemaparan Materi Internet Sehat

Salah satu kegiatan internet sehat yang telah dapat dilakukan oleh pemudapemuda karang taruna adalah memanfaatkan internet sebagai media pembelajaran pembuatan website/blog. 


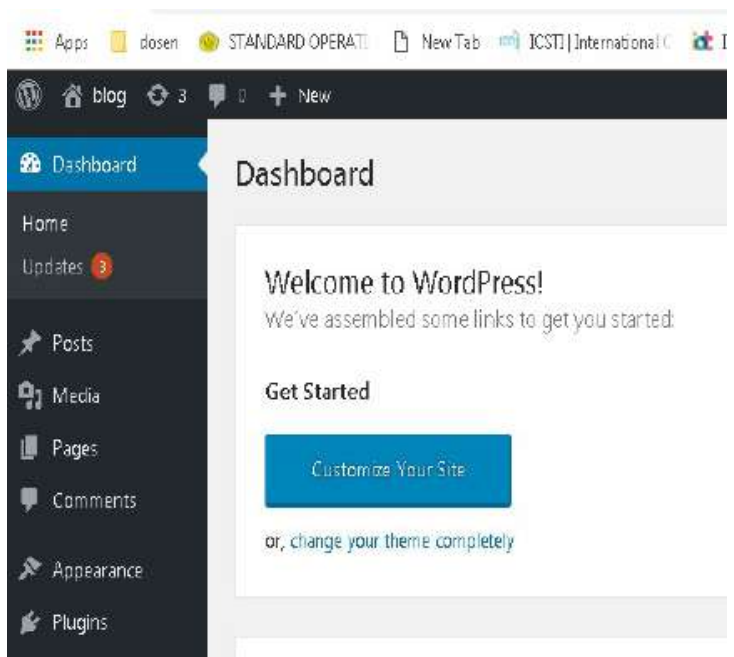

Gambar 7. Pelatihan Pemanfaatan Internet sebagai media belajar pembuatan Wordpress

Evaluasi kegiatan melalui kuesioner kepada peserta pelatihan tidak dapat dilakukan sebab peserta menolak untuk mengisi kuesioner sehingga evaluasi hanya dilakukan dengan metode tanya jawab (post-test). Rekapitulasi pertanyaan yang diajukan serta jawaban dari peserta adalah sebagai berikut:

\section{Tabel 1. Hasil post test}

\begin{tabular}{|c|c|c|c|}
\hline $\begin{array}{l}\mathrm{N} \\
\mathrm{O}\end{array}$ & Pertanyaan & $\begin{array}{l}\text { Jawaban } \\
\text { peserta }\end{array}$ & $\begin{array}{l}\text { Kesim- } \\
\text { pulan }\end{array}$ \\
\hline 1 & $\begin{array}{l}\text { Mengapa } \\
\text { perlu untuk } \\
\text { menjaga } \\
\text { keamanan } \\
\text { akun sosial } \\
\text { media? }\end{array}$ & $\begin{array}{l}\text { 1. Agar tidak } \\
\text { dimanfaat- } \\
\text { kan orang } \\
\text { yang salah } \\
\text { 2. Agar tidak } \\
\text { digunakan } \\
\text { untuk } \\
\text { menipu } \\
\text { saudara/ } \\
\text { kenalan }\end{array}$ & $\begin{array}{l}\text { Benar. } \\
\text { Peserta } \\
\text { memaha- } \\
\text { mi materi } \\
\text { keamanan } \\
\text { yang } \\
\text { diberikan. }\end{array}$ \\
\hline 2 & $\begin{array}{l}\text { Apa } \\
\text { dampak } \\
\text { jika } \\
\text { mengguna- }\end{array}$ & $\begin{array}{l}\text { 1. Kecanduan } \\
\text { 2. Kehabisan } \\
\text { kuota } \\
\text { sehingga }\end{array}$ & $\begin{array}{l}\text { Benar. } \\
\text { Peserta } \\
\text { memaha- } \\
\text { mi materi }\end{array}$ \\
\hline
\end{tabular}

\begin{tabular}{|l|l|l|l|}
\hline & $\begin{array}{l}\text { kan } \\
\text { smartphone } \\
\text { /internet } \\
\text { terlalu } \\
\text { lama? }\end{array}$ & $\begin{array}{l}\text { menjadi } \\
\text { miskin } \\
\text { 3. Sakit mata }\end{array}$ & $\begin{array}{l}\text { keamanan } \\
\text { yang } \\
\text { diberikan. }\end{array}$ \\
\hline 3 & $\begin{array}{l}\text { Bagaimana } \\
\text { cara agar } \\
\text { tidak } \\
\text { kecanduan } \\
\text { sosial } \\
\text { media }\end{array}$ & $\begin{array}{l}\text { 1. Melakukan } \\
\text { aktivitas } \\
\text { yang lain } \\
\text { 2. Berkumpul } \\
\text { bersama ibu- } \\
\text { ibu lain }\end{array}$ & $\begin{array}{l}\text { Benar. } \\
\text { Peserta } \\
\text { memaha- } \\
\text { mi materi } \\
\text { keamanan } \\
\text { yang } \\
\text { diberikan. }\end{array}$ \\
\hline
\end{tabular}

Evaluasi kegiatan pemaparan materi dan pelatihan dilakukan oleh Ketua Karang Taruna Wiratama Mandala. Pengabdian masyarakat ini memperoleh nilai 47 dari rentang nilai 11-55. Hasil tersebut dapat diintepretasikan dalam kategori "baik". Hasil penilaian diisi oleh Ketua Karang Taruna Wiratama Mandala dalam bentuk kuesioner. Pertanyaan yang diajukan dalam kuesioner tersebut meliputi:

1. Relevansi kegiatan terhadap kebutuhan mitra

2. Penilaian terhadap isi, bahan, narasumber

3. Kejelasan waktu pelaksanaan pelatihan

\section{SIMPULAN}

Kesimpulan yang diperoleh dalam pelaksanaan kegiatan pengabdian ini adalah sebagai berikut:

Pertama, kegiatan Pelatihan Internet Sehat dan Pemanfaataanya telah memberikan pemahaman yang jelas dan lengkap kepada peserta khususnya usia remaja dan paruh baya di Banjar Peregae Desa Mengwi. Hal ini tampak pada hasil evaluasi secara langsung di mana pertanyaan-pertanyaan yang diberikan oleh 
narasumber dapat dijawab dengan benar dan lancar.

Kedua, setelah dilaksanakan kegiatan pelatihan, pemanfaatan program internet gratis oleh Pemerintah Kabupaten Badung menurut Karang Taruna di Desa Mengwi menjadi lebih optimal. Hal ini dapat terlihat dari pemanfaatan Internet gratis setelah kegiatan, di mana tidak hanya dimanfaatkan untuk postingan di sosial media dengan konten yang tidak memiliki nilai ekonomis dan permainan menggunakan aplikasi game online, melainkan juga dimanfaatkan untuk membuat media sosialisasi berbasis web sederhana yang memperkenalkan produk dan bernilai ekonomis.

Saran yang dapat disampaikan untuk kegiatan sejenis berikutnya adalah pemilihan waktu kegiatan yang khusus untuk satu pelaksanaan saja, tidak digabung dengan kegiatan lainnya. Gagasan ini timbul berdasarkan observasi kegiatan pemaparan materi dan pelatihan internet sehat yang telah dilaksanakan di Banjar Peregae Desa Mengwi ini berlangsung sebagai rangkaian dari sejumlah kegiatan Karang Taruna Wiratama Mandala. Peserta terkesan lelah meskipun sangat antusias dalam mengikuti kegiatan pelatihan Internet, karena sebelumnya telah mengikuti kegiatan lain.

\section{UCAPAN TERIMA KASIH}

Terima kasih ditujukan kepada Institut Teknologi dan Bisniss STIKOM Bali karena telah memfasilitasi kegiatan pengabdian masyarakat ini melalui program Pengabdian Masyarakat Internal 2019.

\section{DAFTAR PUSTAKA}

Abdi F \& Rachman MA. (2017), Perilaku Pencarian Informasi Wanita yang Tinggal di Daerah Kumuh di Kampung Poncol, Jakarta Selatan, Indonesia. Edulib 7 (1): 24.

Bali Express, (2018), "Tahun Ini, Badung Pasang 1.900 Jaringan Wifi Gratis", https://baliexpress.jawapos.com/read/2018 /01/12/39831/tahun-ini-badung-pasang1900-jaringan-wifi-gratis, diakses pada 06 Oktober 2019

Krisnawati, E. (2015). Pola Penggunaan Internet Oleh Kalangan Remaja Di Kabupaten Semarang. Cakrawala, 4(2).

Kominfo (2019), "Penggunaan Internet di Indonesia",

https://aptika.kominfo.go.id/2019/08/peng gunaan-internet-di-indonesia/, diakses pada 15 Juni 2020

Maya, N. (2015). Fenomena cyberbullying di kalangan pelajar. JISIP: Jurnal Ilmu Sosial dan Ilmu Politik, 4(3).

Rachmatan, R., \& Ayunizar, S. R. (2017). Cyberbullying pada Remaja SMA di Banda Aceh. Insight: Jurnal Pemikiran dan Penelitian Psikologi, 13(2), 67-79.

Rusmana, A. (2015). Penipuan dalam interaksi melalui media sosial (kasus peristiwa penipuan melalui media sosial dalam masyarakat berjejaring). Jurnal Kajian Informasi \& Perpustakaan, 3(2), 187-194

Rifauddin, M. (2016). Fenomena cyberbullying pada remaja. Khizanah alHikmah: Jurnal Ilmu Perpustakaan, Informasi, dan Kearsipan, 4(1), 35-44.

Utami, A. S. F., \& Baiti, N. (2018). Pengaruh media sosial terhadap perilaku 
WIDYABHAKTI

JURNAL ILMIAH POPULER 2(3): 137-145

cyberbullying pada kalangan remaja. Cakrawala-Jurnal Humaniora, 18(2), 257262.

Yusup, P. M., Komariah, N., Prahatmaja, N., \& Samson, C. M. S. (2019).
Pemanfaatan Internet Untuk Penghidupan Di Kalangan Pemuda Pedesaan. BACA: Jurnal Dokumentasi dan InformasI, 40(2), 217-227. 